\title{
Mutational analysis of the Paracoccus denitrificans c-type cytochrome biosynthetic genes CcmABCDG : disruption of ccmC has distinct effects suggesting a role for $\mathrm{CcmC}$ independent of CcmAB
}

\author{
M. Dudley Page $†$ and Stuart J. Ferguson
} Author for correspondence: M. Dudley Page. Tel: +31 20 4447183. Fax: +31204447229.
e-mail: mpage@bio.vu.nl

Department of Biochemistry, University of Oxford, South Parks Road, Oxford, OX1 3QU, UK, and Oxford Centre for Molecular Sciences, New Chemistry Building, South Parks Road, Oxford, OX1 3QT, UK

\begin{abstract}
Each of the Paracoccus denitrificans genes in the c-type cytochrome biogenesis gene cluster CCMABCDG, plus the two flanking genes ORF117 and hisH, were individually disrupted by $\Omega$ insertion. Resultant phenotypes were restored to the wild-type by complementation from a set of plasmids. All of the $\mathrm{ccm}$ genes, but neither ORF117 nor hisH, were required for c-type cytochrome biogenesis; only ccmG was also implicated in the biosynthesis of cytochrome $\mathrm{aa}_{3}$. Disruption of $\mathrm{ccmC}$ or $\mathrm{ccmG}$ resulted in failure to grow on rich media, but disruption of ccmA, ccmB or ccmD did not. The ccmC mutant, but not the $\mathrm{ccm} A, \mathrm{ccmB}$ or $\mathrm{ccmD}$ mutants, also exhibited the increased sensitivity to growth inhibition by oxidized thiol compounds previously observed for the ccmG mutant. In contrast to the ccmG mutant, however, growth of the ccmC mutant on rich media could not be restored by DTT. Siderophore biosynthesis and/or secretion by $P$. denitrificans was also attenuated by disruption of $\mathrm{ccm} C$ and $\mathrm{ccm} G$ but not of $\mathrm{ccm} A, \mathrm{ccmB}$ or $\mathrm{ccmD}$. These results indicate that $\mathrm{CcmC}$ can function independently of $\mathrm{Ccm} A, \mathrm{CcmB}$ and $\mathrm{CcmD}$ despite other evidence that these gene products form an ATP-binding cassette (ABC)-type-transporter with the subunit composition (CcmA $)_{2}-\mathrm{CcmB}-\mathrm{CcmC}$ or $(\mathrm{CcmA})_{2}-\mathrm{CcmB}-\mathrm{CcmC}-\mathrm{CcmD}$, and also suggest a possible link between the functions of $\mathrm{CcmC}$ and $\mathrm{CcmG}$.
\end{abstract}

Keywords: Paracoccus denitrificans, c-type cytochrome biogenesis, putative ABCtransporter, siderophores

\section{INTRODUCTION}

The c-type cytochromes are haemoproteins characterized by covalent attachment of the haem moiety to the cytochrome polypeptide via thioether links between the haem vinyl groups and the thiol groups of two cysteine residues in the conserved motif Cys-X-Y-Cys-His. A number of genes have so far been identified as essential for $c$-type cytochrome biogenesis in Gram-negative bacteria, for example ccmABCDEFGH in Escherichia

†Present address: Faculty of Biology, Vrije Universiteit, De Boelelaan 1087, 1081 HV Amsterdam, The Netherlands.

Abbreviations: $A B C$, ATP-binding cassette; CAS, chrome azurol sulphonate; HEDS, 2-hydroxyethyldisulphide; TMPD, tetramethylphenylenediamine.

The GenBank accession number for the sequence determined in this work is $Z 71971$. coli and belABCDX, ccl12 and cycH in Rhodobacter capsulatus (Thöny-Meyer, 1997). Of these, ccmA/helA, $c \mathrm{cmB} /$ helB and $c \mathrm{~cm} C /$ helC and their homologues in other Gram-negative bacteria appear to encode the components of an ATP-binding cassette (ABC)-transporter (Thöny-Meyer, 1997; Kranz, 1998; Page et al., 1998). In $R$. capsulatus the helABC genes are located in a five-gene cluster, helABCDX (Beckman et al., 1992; Beckman \& Kranz, 1993), and a similarly organized cluster of homologous genes has recently been found in the closely related Paracoccus denitrificans (ccmABCDG; Page et al., 1997; Page \& Ferguson, 1997). The putative ABC-transporter has been suggested to have the subunit composition (HelA) ${ }_{2}$-HelB-HelC (Kranz \& Beckman, 1995), a proposal supported by an analysis of the availible HelB/CcmB- and $\mathrm{HelC} / \mathrm{CcmC}$ homologous sequences which indicated that all members of both groups of proteins exhibit a sequence motif 
characteristic of the membrane-integral components of bacterial ABC-transporters and proposed to mediate their interaction with the more hydrophilic ATPase subunit (in this case HelA/CcmA; Page et al., 1997). The demonstration that in R. capsulatus both HelB and HelC are required for stability of HelA, and that HelC can be co-immunoprecipitated with HelA, has provided some evidence for this model (Goldman et al., 1997). Additionally, co-immunoprecipitation of HelD with HelA has led to the suggestion that the putative transporter may have the unusual subunit composition (HelA) ${ }_{2}$-HelB-HelC-HelD (Goldman et al., 1997). It has been suggested that the role of the putative $(\mathrm{HelA})_{2^{-}}$ HelB-HelC $( \pm$ HelD $)$ and related complexes may be translocation of haem across the cytoplasmic membrane for attachment to periplasmic $c$-type cytochrome apoproteins (Kranz \& Beckman, 1995; Thöny-Meyer, 1997; Kranz et al., 1998), but this, and indeed whether they are functional transporters at all, has yet to be established.

We have previously reported the phenotypic consequences of disruption of $\mathrm{ccm} G$ in P. denitrificans (Page $\&$ Ferguson, 1997); one unexpected outcome of this work was that disruption of $\mathrm{ccm} G$ led not only to loss of $c$-type cytochromes but also to absence of cytochrome $a a_{3}$ and to failure to grow in rich media, indicating that CcmG had a wider role in the metabolism of this organism than had previously been suspected. We now report the phenotypic consequences of disruption of $P$. denitrificans $c c m A, c c m B, c c m C$ and $c c m D$. Complementation and phenotypic analyses of the resulting mutant strains have revealed that disruption of $\mathrm{cmC}$ leads to far more severe phenotypic consequences than disruption of either $c c m A, c c m B$ or $c c m D$. The implications of this result for the existence and organization of the putative $\mathrm{ABC}$-transporter are discussed.

\section{METHODS}

Bacterial strains, plasmids and growth conditions. The strains and plasmids used in this study are listed in Table 1. P. denitrificans strains were grown aerobically in the minimal medium of Burnell et al. (1975) containing either sodium succinate $(50 \mathrm{mM})$ or choline $(0.5 \%, \mathrm{w} / \mathrm{v})$, or in the medium of Alefounder \& Ferguson (1981) containing 0.5\% (v/v) methanol. All other conditions were as described by Page \& Ferguson (1997). Antibiotics were added to the following final concentrations $\left(\mu \mathrm{g} \mathrm{ml}^{-1}\right)$ : ampicillin, 100; kanamycin, 25 (for E. coli) or 100 (for P. denitrificans); rifampicin, 100; spectinomycin, 25 (for E. coli) or 100 (for P. denitrificans); streptomycin, 60; tetracycline, 10.

Analytical methods. Preparation of total soluble protein fractions from $P$. denitrificans strains, determination of protein, Nadi testing, SDS-PAGE and staining for haem were as described previously (Page \& Ferguson, 1995). Preparation and solubilization of membranes from $P$. denitrificans strains, spectrophotometry, and determination of cytochrome and tetramethylphenylenediamine (TMPD) oxidase activities were as described by Page \& Ferguson (1997). Siderophore production/secretion was assessed on chrome azurol sulphonate (CAS) agar plates prepared as described by Schwyn \&
Neilands (1987), except that the MM9-based growth medium was replaced by the minimal medium of Burnell et al. (1975) containing sodium acetate $(20 \mathrm{mM})$ as sole carbon and energy source. Cells grown aerobically in succinate minimal medium without added iron $\left(10 \mu \mathrm{l}\right.$ at an $\mathrm{OD}_{650}$ of $\left.0 \cdot 5-0 \cdot 6\right)$ were spotted onto the centre of the plates and incubated at $30^{\circ} \mathrm{C}$ for $7 \mathrm{~d}$.

General DNA manipulations. General DNA manipulations were as described by Sambrook et al. (1989). DNA sequencing was performed using Sequenase version 2.0 (Amersham) and M13 universal primers.

Construction of plasmids for interposon mutagenesis. Two plasmids containing Pd1222 genomic DNA recovered from the $c c m A:: \operatorname{Tn} 5$ mutant HN53 were used as the source of DNA for the construction of mutagenic plasmids. These were pDP535, containing a $4.2 \mathrm{~kb}$ Sall fragment comprising the $5^{\prime}$ region of Tn5 plus $1.7 \mathrm{~kb}$ of HN53 genomic DNA, and pDP533, containing a $6.7 \mathrm{~kb}$ Sall fragment comprising the $3^{\prime}$ region of Tn 5 plus $3.7 \mathrm{~kb}$ of HN53 genomic DNA (Page et al., 1997). Mutagenesis of $\mathrm{ccm} G$ has been described previously (Page \& Ferguson, 1997). The SalI-HpaI segment from pDP535 was cloned into SalI/SmaI-cut pARO181 to create pDP30A; this was then (i) cut with $X h o I$ and ligated to the $\Omega$ cassette isolated from Sall-cut pUX $\Omega$ to create pDP301M, (ii) cut with EcoRV and ligated to the $\Omega$ cassette isolated from SmaI-cut pHP45 $\Omega$ to create pDP302M, and (iii) partially digested with $B g l \mathrm{II}$ and ligated to the $\Omega$ cassette isolated from BamHI-cut pHP $45 \Omega$ to create pDP303M. The BamHI-HpaI segment from pDP533 was cloned in pARO181 cut with BamHI and SmaI to create pDP30B; this was then cut with ApaI, ligated to an adaptor formed from the complementary oligonucleotides (5'-CAAGATATCAAGGGCC-3') and (5'CTTGATATCTTGGGCC-3') to create pDP30BL1, which was cut with $E c o R V$ and ligated to the $\Omega$ cassette isolated from

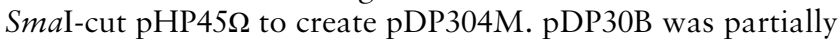
digested with $\mathrm{NcoI}$ and ligated to an adaptor formed from the complementary oligonucleotides (5'-CATGGTTCTCGAGTTC-3') and (5'-CTAGGAACTCGAGAAC- $\left.3^{\prime}\right)$ to create pDP30BL2, which was cut with $X h o$ I and ligated to the $\Omega$ cassette isolated from SalI-cut pUX $\Omega$ to form pDP305M. The $0.8 \mathrm{~kb} \mathrm{BamHI}$ fragment from pDP533 was cloned in pARO181 to create pDP30C, which was then cut with $M s c \mathrm{I}$ and ligated to the $\Omega$ cassette isolated from $S m a \mathrm{I}$-cut pHP $45 \Omega$ to create pDP306M. The $1.7 \mathrm{~kb}$ BamHI-SalI fragment from pDP533 was cloned in pARO181 to create pDP30D, which was cut with EcoRV and ligated to the $\Omega$ cassette from SmaI-cut pHP $45 \Omega$ to create pDP308M. The ApaI-BamHI segment from pDP533 was cloned in pBluescript, excised with BamHI/KpnI and cloned in pARO181 to create pDP30E, which was then cut with BamHI plus SalI and ligated to the $1.7 \mathrm{~kb}$ BamHI-SalI fragment from pDP30D to create pDP30F. This plasmid was cut with $\mathrm{BamHI}$ and ligated to the $\Omega$ cassette from BamHI-cut pHP45 $\Omega$ to create pDP309M. Mutagenic plasmids were introduced into Pd1222 by conjugation, employing pRK2013 as helper plasmid (Ditta et al., 1980) and mated cells plated and screened on solid minimal media. In the case of pARO181based mutagenic plasmids, streptomycin-resistant exconjugants were screened for resistance to kanamycin, a streptomycin-resistant, kanamycin-sensitive phenotype indicating $\Omega$ integration and pARO181 elimination.

Confirmation of the positions of $\Omega$ cassette integration in DP302-DP309. Genomic DNA was isolated from DP302DP309 and the mutagenized $c c m A B C D G-h i s H$ regions cloned in pUC18 as $7 \cdot 1 \mathrm{~kb}$ SalI fragments, using the spectinomycin resistance of the $\Omega$ cassette as a selectable marker, to create the plasmids pDP302R-pDP309R. Segments of P. denitrificans 
Table 1. Strains and plasmids used

\begin{tabular}{|c|c|c|}
\hline Strain or plasmid & Characteristics & Source or reference \\
\hline \multicolumn{3}{|l|}{ P. denitrificans } \\
\hline $\operatorname{Pd} 1222$ & $\mathrm{Rf}^{\mathrm{R}} \mathrm{Sp}^{\mathrm{R}}$, restriction-deficient derivative of NCIMB 8944 & de Vries et al. (1989) \\
\hline DP301 & Pd1222 with $\Omega$ cassette inserted in ORF117 XhoI site (see Fig. 1) & This study \\
\hline DP302 & $\operatorname{Pd} 1222$ with $\Omega$ cassette inserted in ORF117 EcoRV site (see Fig. 1) & This study \\
\hline DP303 & $\operatorname{Pd} 1222 \mathrm{ccm} A:: \Omega$ (see Fig. 1) & This study \\
\hline DP304 & $\operatorname{Pd} 1222 \mathrm{ccmB}:: \Omega$ (see Fig. 1$)$ & This study \\
\hline DP305 & $\operatorname{Pd} 1222$ ccm $C:: \Omega$ (see Fig. 1) & This study \\
\hline DP306 & $\operatorname{Pd} 1222 \mathrm{ccmD}:: \Omega$ (see Fig. 1) & This study \\
\hline DP307 & $\operatorname{Pd} 1222 \mathrm{ccm} G:: \Omega$ (see Fig. 1) & This study \\
\hline DP308 & Pd1222 hisH:: $\Omega$ (see Fig. 1) & This study \\
\hline DP309 & $\operatorname{Pd} 1222 \Delta c c m C D G:: \Omega$ (see Fig. 1) & This study \\
\hline \multicolumn{3}{|l|}{ E. coli } \\
\hline JM83 & ara $\Delta($ lac-proAB) rspL $\phi 80$ lacZ $\Delta \mathrm{M} 15$ & Yanisch-Perron et al. (1985) \\
\hline $\mathrm{DH} 5 \alpha$ & $\begin{array}{l}\text { deoR endA1 gyrA96 hsdR17 }\left(\mathrm{r}_{\mathrm{k}}^{-} \mathrm{m}_{\mathrm{k}}^{+}\right) \text {recA1 relA1 supE44 thi-1 } \\
\Delta\left(\text { lacZYA-argFV169) } \phi 80 \text { slacZ } \Delta \mathrm{M} 15 \mathrm{~F}^{-} \lambda^{-}\right.\end{array}$ & Clontech \\
\hline S17-1 & $\begin{array}{l}\mathrm{C} 600: \mathrm{RP}-4 \text { 2-Tc::Mu-Km::Tn7 hsdR } h s d M^{+} r e c A ; \text { plasmid transfer } \\
\text { (tra) locus integrated in chromosome }\end{array}$ & Simon et al. (1983) \\
\hline \multicolumn{3}{|l|}{ Plasmids } \\
\hline pUC18 & $\mathrm{Ap}^{\mathrm{R}}$, cloning vector & Yanisch-Perron et al. (1985) \\
\hline pBluescript SK II $(+)$ & $\mathrm{Ap}^{\mathrm{R}}$, cloning vector & Stratagene \\
\hline pLITMUS 28 & $\mathrm{Ap}^{\mathrm{R}}$, cloning vector & New England Biolabs \\
\hline pUC4K & $\mathrm{Ap}^{\mathrm{R}} \mathrm{Km}^{\mathrm{R}}$, pUC4 carrying Tn903 $\mathrm{Km}^{\mathrm{R}}$ cassette & Pharmacia \\
\hline $\mathrm{pHP} 45 \Omega$ & $A p^{R} S p^{R}, p H P 45$ carrying $S p^{R} / S m^{R} \Omega$ cassette & Prentki \& Krisch (1984) \\
\hline $\mathrm{pUX} \Omega$ & $\mathrm{Ap}^{\mathrm{R}} \mathrm{Sp}^{\mathrm{R}}$, as $\mathrm{pHP} 45 \Omega, \Omega$ cassette flanked by extended polylinkers & Prentki \& Krisch (1984) \\
\hline pRK2013 & $\mathrm{Km}^{\mathrm{R}}$, helper plasmid; carries tra locus & Ditta et al. (1980) \\
\hline pARO181 & $\mathrm{Km}^{\mathrm{R}}$, mobilizable suicide vector & Parke (1990) \\
\hline pRK415-1 & $\mathrm{Tc}^{\mathrm{R}}$, mobilizable broad-host-range vector & Parke (1990) \\
\hline $\mathrm{pXBF}, \mathrm{pXBR}$ & $\begin{array}{l}\text { pRK } 415-1 / 1.9 \mathrm{~kb} \text { XhoI-BamHI DNA fragment with } c c m A+c c m B \text { in } \\
\text { 'forward' and 'reverse' orientations (see Fig. } 1 \text { and Methods) }\end{array}$ & This study \\
\hline $\mathrm{pXAF}, \mathrm{pXAR}$ & $\begin{array}{l}\text { pRK } 415-1 / 0 \cdot 9 \mathrm{~kb} \text { XhoI-ApaI DNA fragment with } c c m A \text { in 'forward' } \\
\text { and 'reverse' orientations (see Fig. } 1 \text { and Methods) }\end{array}$ & This study \\
\hline $\mathrm{pBgBF}, \mathrm{pBgBR}$ & $\begin{array}{l}\text { pRK } 415-1 / 1.4 \mathrm{~kb} B g l \mathrm{II}-\text { Bam HI DNA fragment with } c c m B \text { in } \\
\text { 'forward' and 'reverse' orientations (see Fig. } 1 \text { and Methods) }\end{array}$ & This study \\
\hline pAHF, pAHR & $\begin{array}{l}\text { pRK415-1/2.3 kb ApaI-HindIII DNA fragment with } c c m C D G \text { in } \\
\text { 'forward' and 'reverse' orientations (see Fig. } 1 \text { and Methods) }\end{array}$ & This study \\
\hline pAPvF, pAPvR & $\begin{array}{l}\text { pRK415-1/1.8 kb ApaI-PvuII DNA fragment with } c c m C D \text { in } \\
\text { 'forward' and 'reverse' orientations (see Fig. } 1 \text { and Methods) }\end{array}$ & This study \\
\hline $\mathrm{pMF}, \mathrm{pMR}$ & $\begin{array}{l}\text { pRK } 415-1 / 0 \cdot 85 \mathrm{~kb} \mathrm{MscI} \mathrm{DNA} \mathrm{fragment} \mathrm{with} c c m C \text { in 'forward' and } \\
\text { 'reverse' orientations (see Fig. } 1 \text { and Methods) }\end{array}$ & This study \\
\hline pNHF, pNHR & $\begin{array}{l}\text { pRK415-1/1.2 kb NcoI-HindIII DNA fragment with } c c m C D \text { in } \\
\text { 'forward' and 'reverse' orientations (see Fig. } 1 \text { and Methods) }\end{array}$ & This study \\
\hline $\mathrm{pBF}, \mathrm{pBR}$ & $\begin{array}{l}\text { pRK } 415-1 / 0.8 \mathrm{~kb} \text { BamHI DNA fragment with } c c m D \text { in 'forward' and } \\
\text { 'reverse' orientations (see Fig. } 1 \text { and Methods) }\end{array}$ & This study \\
\hline pCR1F, pCR1R & $\begin{array}{l}\text { pRK } 415-1 / 1 \cdot 0 \mathrm{~kb} \text { HindIII PCR product with } c c m D G \text { in 'forward' and } \\
\text { 'reverse' orientations (see Fig. } 1 \text { and Methods) }\end{array}$ & This study \\
\hline pMHF, pMHR & $\begin{array}{l}\text { pRK415-1/1.2 kb MscI-HindIII DNA fragment with } c c m D G \text { in } \\
\text { 'forward' and 'reverse' orientations (see Fig. } 1 \text { and Methods) }\end{array}$ & This study \\
\hline
\end{tabular}

genomic DNA upstream and downstream of the $\Omega$ cassette were then subcloned in pUC18 as SalI-HindIII and HindIII fragments, respectively (see Fig. 1); both sets of fragments contained a region of DNA derived from the $\Omega$ cassette, permitting confirmation of the $\Omega$ cassette-genomic DNA junction region by sequencing.
Construction of plasmids for complementation analysis. Segments of the intact $P$. denitrificans $c c m A B C D G$ gene region cloned in the series of plasmids pDP302R-pDP309R (see above) were subcloned in the broad-host-range vector pRK415-1. The $1.9 \mathrm{~kb}$ XhoI-BamHI fragment carrying both $c c m A$ and $c c m B$ was cloned in pBluescript, then excised with 
(i) KpnI plus $S a c \mathrm{I}$ and (ii) KpnI plus $\mathrm{XbaI}$, and cloned in pRK415-1 to create $\mathrm{pXBF}$ and $\mathrm{pXBR}$, respectively. The $0 \cdot 9 \mathrm{~kb}$ $X h o I-A p a \mathrm{I}$ fragment carrying only $c c m A$ was also cloned in pBluescript, then excised with (i) $K p n I$ plus $X b a \mathrm{I}$ and (ii) $K p n \mathrm{I}$ plus $S a c I$, and cloned in pRK415-1 to create pXAF and pXAR, respectively. The $1.4 \mathrm{~kb} B g l \mathrm{II}-\mathrm{Bam} \mathrm{HI}$ fragment carrying only $c \mathrm{cmB}$ was cloned in both orientations in BamHI-cut pRK4151 to create $\mathrm{pBgBF}$ and $\mathrm{pBgBR}$. The $2.3 \mathrm{~kb}$ ApaI-HindIII fragment carrying $c c m C, c c m D$ and $c c m G$ was cloned in pBluescript, then excised with (i) KpnI plus $S a c$ I and (ii) KpnI plus XbaI, and cloned in pRK415-1 to create pAHF and pAHR, respectively. The $855 \mathrm{bp} \mathrm{MscI} \mathrm{fragment} \mathrm{carrying} \mathrm{only}$ $c c m C$ was cloned in pBluescript that had been digested with EcoRV, then excised with (i) EcoRI plus HindIII and (ii) KpnI plus $X b a I$, and cloned in pRK415-1 to create $\mathrm{pMF}$ and $\mathrm{pMR}$, respectively. The $1.8 \mathrm{~kb} A p a \mathrm{I}-P v u \mathrm{II}$ fragment carrying $c \mathrm{~cm} C$ and $c c m D$ was cloned in pBluescript that had been cut with ApaI plus EcoRV, then excised with (i) KpnI plus $S a c$ I and (ii) $K p n I$ plus XbaI, and cloned in PRK415-1 to create pAPvF and pAPvR, respectively. The $0.8 \mathrm{~kb} B a m \mathrm{HI}$ fragment carrying only $c c m D$ was cloned in both orientations in pRK415-1 to create $\mathrm{pBF}$ and $\mathrm{pBR}$, respectively. The $1.2 \mathrm{~kb}$ NcoIHindIII fragment carrying $c c m D$ and $c c m G$ was cloned in pLITMUS 28, then excised with (i) SacI plus PstI and (ii) EcoRI plus XbaI, and cloned in pRK415-1 to create pNHF and pNHR, respectively. The 879 bp MscI-HindIII fragment containing only $\mathrm{ccm} G$ was cloned in pBluescript that had been digested with EcoRV plus HindIII, then excised with (i) KpnI plus $\mathrm{XbaI}$ and (ii) EcoRI plus HindIII, and cloned in pRK4151 to create pMHF and pMHR, respectively. A 1009 bp segment of DNA comprising $c c m G, c c m D$ and the 3 '-terminal 24 bp of $c c m C$ was PCR-amplified from plasmid DNA using the primers 5'-AAGCTTATTGCTGGCAAGGGAGAAC-3' and $5^{\prime}$-CGAGGAAAGCTTCACGACG-3' and cloned in EcoRVdigested pBluescript, resequenced, then excised with (i) KpnI plus $\mathrm{XbaI}$ and (ii) $K p n \mathrm{I}$ plus EcoRI and cloned in pRK415-1 to create pCR1F and pCR1R, respectively. All pRK415-1-derived plasmids were transformed into E. coli S17-1 for transfer to $P$. denitrificans strains in a biparental mating procedure (Bagdasarian et al., 1981). Conjugations of DP305, DP307 and DP309 with E. coli strains were performed on minimal succinate agar as described by Oozeer et al. (1993). After mating, cells were replica-plated onto methanol minimal media containing streptomycin. Complemented cells were visible after $3-5 \mathrm{~d}$; absence of visible colonies after $10 \mathrm{~d}$ was scored as inability to complement.

\section{RESULTS}

\section{Structure of the ccmABCDG gene region of $P$. denitrificans}

The $P$. denitrificans $c c m A B C D G$ gene region is located on a $5 \cdot 1 \mathrm{~kb}$ Sall fragment of genomic DNA which has now been completely sequenced. It contains two partial and seven complete large ORFs with a codon usage typical of genes in P. denitrificans (Baker et al., 1998); these are $5^{\prime}{ }^{\prime}$ secF-ORF117-ccmA-ccmB-ccm C-ccmDccmG-hisH-ORF $>59^{\prime}-3^{\prime}$ (Fig. 1).

\section{Construction of interposon mutants in the cCmABCDG gene region}

A system for $\Omega$ interposon mutagenesis of $P$. denitrificans has been described previously (Page \& Ferguson, 1997). The $\Omega$ interposon cassette was introduced into con- venient restriction sites within $c c m A, c c m B, c c m C$, $c \mathrm{cmD}, \mathrm{ccmG}$ and $h i s H$, and at two restriction sites within ORF117. A strain in which the DNA region between the BamHI sites in $c c m C$ and $c c m G$ was deleted and replaced by the $\Omega$ cassette was also constructed. The strains generated were named DP301 to DP309 (Fig. 1, Table 1).

The exact positions of $\Omega$ integration in DP302-DP309 were confirmed by marker rescue of the mutagenized ORF117-ccmABCDG-hisH regions and sequencing of the $\Omega$ cassette-genomic DNA junctions. In the case of DP301, marker rescue was not achieved and the position of $\Omega$ integration was instead confirmed by hybridization.

\section{Growth properties of the interposon mutants}

The growth properties of the $c c m G:: \Omega$ mutant DP307 have been reported previously (Page \& Ferguson, 1997). Mutants DP302-DP307 and DP309 were incapable of growth on methanol or of anaerobic growth with nitrate as terminal electron acceptor, both growth modes of which require the synthesis of $c$-type cytochromes (Willison \& John, 1979; Baker et al., 1998), and were unable to oxidize dimethylphenylenediamine (the Nadi reaction; Marrs \& Gest, 1973), a test for the presence of the cytochrome $c$-cytochrome- $c$ oxidase segment of the bacterial electron transport chain. In spite of these defects in electron transport, DP302-DP306 grew at similar rates to the parental strain Pd1222 on succinate minimal media (Fig. 2); mutants of $P$. denitrificans pleiotropically deficient in $c$-type cytochromes are able to grow aerobically at a rate similar to that of the parental strain because the bacterium also synthesizes a ubiquinol oxidase (Willison \& John, 1979; Baker et al.,

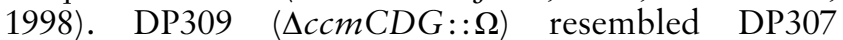

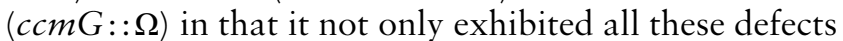
in electron transport but also grew at a reduced rate compared to Pd1222 on succinate minimal media (doubling time $2 \cdot 1 \mathrm{~h}$ compared to $1.3 \mathrm{~h}$; Fig. 2). Like DP307, DP309 exhibited reduced pigmentation compared to Pd1222; colonies formed on solid minimal media were off-white rather than brownish pink. In contrast, DP301 and DP308 were capable of growth on methanol and of anaerobic growth with nitrate as terminal electron acceptor, and were Nadi-positive. Mutant DP308 (hisH:: $\Omega$ ) was prototrophic, indicating either that the $P$. denitrificans synthesizes two functional imidazole acetol phosphate transaminase enzymes, or that the gene identified here as his $H$ by homology does not encode a functional enzyme and that the true bis $H$ gene lies elswhere in the genome, or that there is a HisHindependent route for the transamination of imidazole acetol phosphate to histidinol phosphate in P. denitrificans.

\section{Cloning of the $c c m A B C D G$ gene region and complementation of interposon mutants}

Each of the interposon mutants was subjected to complementation analysis in order to clarify the effects of individual $\Omega$ insertions and to show that the pheno- 

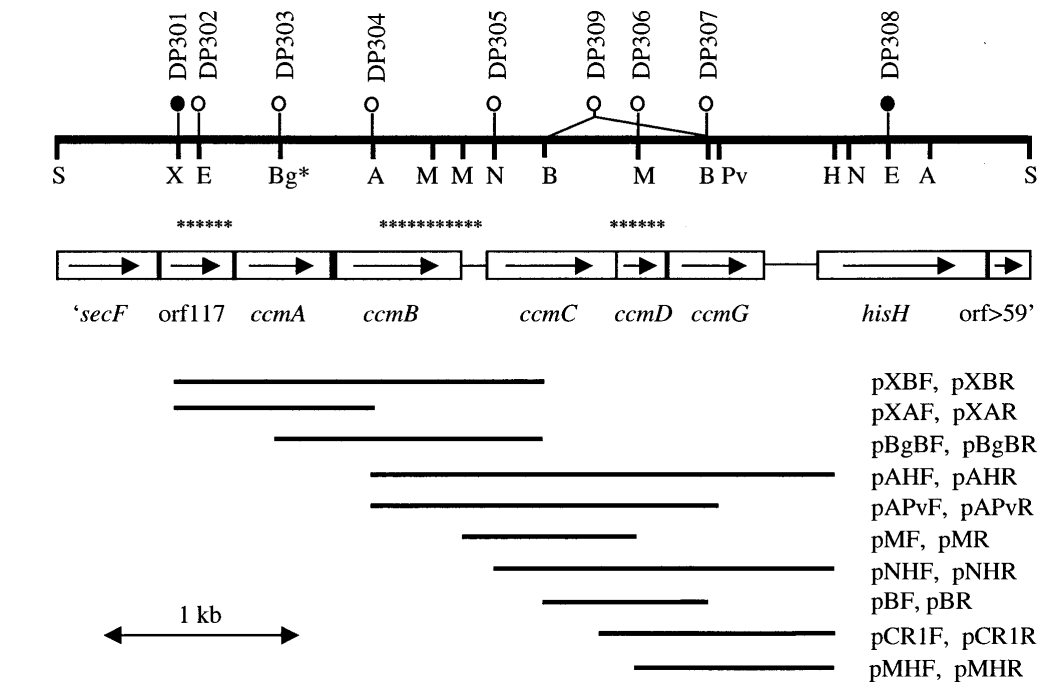

pXBF, pXBR PXAF, PXAR $\mathrm{pBgBF}, \mathrm{pBgBR}$ PAHF, PAHR PAPvF, pAPvR pMF, pMR pNHF, pNHR pBF, pBR pCR1F, pCR1R pMHF, pMHR
Fig. 1. Physical and restriction map of the $5.1 \mathrm{~kb}$ Sall DNA fragment harbouring the $P$. denitrificans 'secF-ORF117-ccmABCDG-hisHORF $>59^{\prime}$ gene region. A, Apal; B, BamHI; $\mathrm{Bg}, B g / l \mathrm{I} ; \mathrm{E}$, EcoRV; $\mathrm{H}$, Hindlll; M, Mscl; N, Ncol; Pv, Pvull; S, Sall; X, Xhol; *, site not unique. Circles indicate the sites of $\Omega$ cassette insertion in the various mutant strains: O, cytochromes c present; $\bigcirc$, cytochromes $c$ absent. $* * * *$, approximate locations of promoters as suggested by complementation and phenotypic analyses of mutants. Wild-type DNA fragments cloned into pRK415-1 for complementation analysis are indicated beneath the map. $F$ denotes the cloned DNA fragment oriented such that any ORFs on it were under the control of the pRK415-1 lac promoter or a promoter region upstream of it; $R$ indicates the reverse orientation.

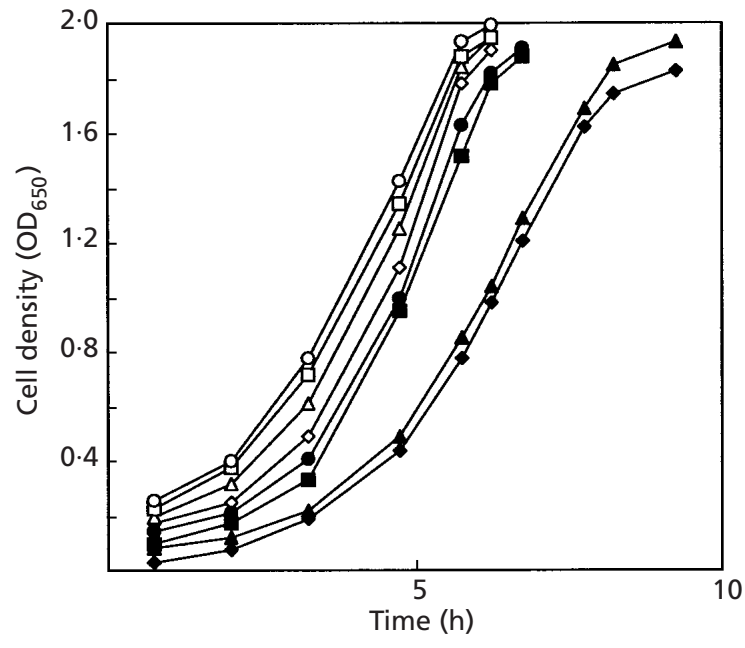

Fig. 2. Growth of the mutant strains in minimal medium. Cells pregrown in succinate minimal medium were inoculated into succinate minimal medium and cell density (as $\mathrm{OD}_{650}$ ) monitored. $\mathrm{O}, \mathrm{Pd} 1222 ; \square, \mathrm{DP} 302 ; \triangle, \mathrm{DP} 303 ; \diamond, \mathrm{DP} 304 ; 0$, DP305; 口, DP306; $\mathbf{\Delta}, \mathrm{DP} 307 ; \bullet, \mathrm{DP} 309$. The growth curves exhibited by DP301 and DP308 were identical to that exhibited by Pd1222 and have been omitted for the sake of clarity.

types obtained were due solely to the introduced $\Omega$ interposon. The intact $P$. denitrificans $c c m A B C D G$ gene region isolated from DP308 (see above) was used as the source of DNA for the construction of plasmids for complementation analysis. These plasmids were introduced into DP302-DP307 and DP309 and complementation assessed on methanol minimal media containing streptomycin. Details of these experiments are given in Fig. 1 and Tables 1 and 2.

Complementation of the DP302, DP303 and DP304 mutations by both XBF (F, or forward, denotes the orientation of a cloned DNA fragment such that any
ORFs on it were placed under the control of the pRK4151 lac promoter or a promoter region upstream of it; $\mathrm{R}$ indicates the reverse orientation) and XBR indicates that the Xhol-BamHI fragment contains at least one endogenous promoter for $c \mathrm{~cm} A$ and $c \mathrm{cmB}$. Failure of the XhoI-ApaI fragment cloned in pXAF or pXAR to complement the DP302 or DP303 mutations indicates that $c \mathrm{cmB}$ is not expressed in these strains and thus that there is no separate promoter for $c \mathrm{cmB}$ within the $3^{\prime}$ region of $c c m A$; this conclusion is supported by the observation that the DP304 mutation was complemented by $\mathrm{pBgBF}$ but not by $\mathrm{pBgBR}$. These data suggest that in $P$. denitrificans $c c m A$ and $c c m B$ are cotranscribed from a promoter upstream of $c \mathrm{~cm} A$ and that this promoter is disrupted by the $\Omega$ interposon in DP302. Complementation of the DP302, DP303 and DP304 mutations by plasmids containing $c c m A B$ and of the DP304 mutation by a plasmid containing $c c m B$ alone indicates that $\Omega$ insertions in $c c m A, c c m B$ or the $c c m A B$ promoter region do not eliminate the expression of $\mathrm{ccm} C, \mathrm{ccmD}$ or $\mathrm{ccm} G$. This was confirmed by complementation of DP305, DP306, DP307 and DP309 by both pAHF and pAHR, indicating that the ApaI-HindIII fragment contains at least one endogenous promoter for $\mathrm{ccm} C, \mathrm{ccmD}$ and $\mathrm{ccm} G$. This conclusion was supported by complementation of DP305 and DP306 by both $\mathrm{pAPvF}$ and $\mathrm{pAPvR}$. Complementation of the $c c m G:: \Omega$ mutation in DP307 by both pNHF and pNHR, and both pCR1F and pCR1R (all carrying both $c c m D$ and $c c m G$ ), indicates that there is a promoter for $c \mathrm{~cm} G$ within $\mathrm{ccmD}$ or the 3'-terminal region of $\mathrm{ccmC}$. Complementation of the $c c m D:: \Omega$ mutation in DP306 by pBF and $\mathrm{pNHF}$ but not by $\mathrm{pBR}$ or $\mathrm{pNHR}$, and the failure of $\mathrm{pMF}$ to complement the $c c m C:: \Omega$ lesion, indicates that there is no separate promoter for $c \mathrm{cmD}$ within $\mathrm{ccm} C$ and thus that $c \mathrm{~cm} C$ and $c \mathrm{cmD}$ are likely to be cotranscribed from a promoter upstream of $c \mathrm{~cm} C$. However, the failure of $\mathrm{pBF}$ (carrying $c \mathrm{cmD}$ but not $c \mathrm{~cm} C$ ), pNHF and pCR1F (carrying $\mathrm{ccmD}$ and $\mathrm{ccm} G$ but not $\mathrm{ccm} C$ ) to complement 
Table 2. Complementation data for the various $\Omega$ interposon mutants in the ORF117-ccmABCDG-hisH gene region

The criterion of complementation was restoration of growth on methanol minimal media containing streptomycin. F denotes the cloned DNA fragment oriented such that any ORFs on it were under the control of a vector promoter; R indicates the reverse orientation.

\begin{tabular}{|c|c|c|c|c|c|c|c|c|c|c|c|c|c|c|c|}
\hline \multirow[t]{3}{*}{ Plasmid } & \multirow{3}{*}{$\begin{array}{l}\text { Intact genes } \\
\text { encoded }\end{array}$} & \multicolumn{14}{|c|}{ Complementation of growth on methanol of: } \\
\hline & & \multicolumn{2}{|c|}{ DP302 } & \multicolumn{2}{|c|}{ DP303 } & \multicolumn{2}{|c|}{ DP304 } & \multicolumn{2}{|c|}{ DP305 } & \multicolumn{2}{|c|}{ DP306 } & \multicolumn{2}{|c|}{ DP307 } & \multicolumn{2}{|c|}{ DP309 } \\
\hline & & $\mathrm{F}$ & $\mathbf{R}$ & $\mathrm{F}$ & $\mathbf{R}$ & $\mathrm{F}$ & $\mathbf{R}$ & $\mathrm{F}$ & $\mathbf{R}$ & F & $\mathbf{R}$ & $\mathbf{F}$ & $\mathbf{R}$ & $\mathrm{F}$ & $\mathbf{R}$ \\
\hline $\mathrm{pXBF} / \mathrm{pXBR}$ & $c c m A, c c m B$ & + & + & + & + & + & + & - & - & & & & & & \\
\hline $\mathrm{pXAF} / \mathrm{pXBR}$ & ccmA & - & - & - & - & - & - & - & - & & & & & & \\
\hline $\mathrm{pBgBF} / \mathrm{pBgBR}$ & $c c m B$ & - & - & - & - & + & - & - & - & & & & & & \\
\hline $\mathrm{pAHF} / \mathrm{pAHR}$ & $c c m C, c c m D, c c m G$ & & & & & - & - & + & + & + & + & + & + & + & + \\
\hline $\mathrm{pAPvF} / \mathrm{pAPvR}$ & $c c m C, c c m D$ & & & & & - & - & + & + & + & + & - & - & - & - \\
\hline $\mathrm{pMF} / \mathrm{pMR}$ & $\mathrm{ccm} C$ & & & & & & & - & - & - & - & & & & \\
\hline $\mathrm{pBF} / \mathrm{pBR}$ & $c c m D$ & & & & & & & - & - & + & - & - & - & & \\
\hline pNHF/pNHR & $c c m D, c c m G$ & & & & & & & - & - & + & - & + & + & - & - \\
\hline pCR1F/pCR1R & $c c m D, c c m G$ & & & & & & & & & + & - & + & + & - & - \\
\hline pMHF/pMHR & $\mathrm{ccm} G$ & & & & & & & & & - & - & + & - & - & - \\
\hline
\end{tabular}

the $c c m C:: \Omega$ mutation in DP305 confirms that $c c m C$ is essential for $c$-type cytochrome assembly in $P$. denitrificans. Complementation of the $c \mathrm{~cm} G:: \Omega \mathrm{mu}-$ tation in DP307 by both pCR1F and pCR1R indicates the presence of a promoter for $\mathrm{ccm} G$ within $c \mathrm{cmD}$, whilst complementation by pMHF but not pMHR suggests that at least some elements of this promoter lie upstream of the $c c m D M s c$ I site.

\section{c-type cytochrome biogenesis in the interposon mutants}

Total soluble and membrane fractions of DP301-DP309 grown with choline, a gratuitous inducer of $c$-type cytochromes associated with methylotrophic growth (Harms \& van Spanning, 1991), were analysed by spectrophotometry. Membranes isolated from DP302DP307 and DP309 contained $b$-type cytochromes at levels similar to those observed in membranes prepared from choline-grown Pd1222 but were devoid of $c$-type cytochromes (Fig. 3a). Cytochromes $c$ were also absent from total soluble fractions from DP302-DP307 and DP309 (Fig. 3b). In contrast, total soluble and membrane fractions from DP301 and DP308 contained wild-type levels of $c$-type cytochromes. These results were confirmed by SDS-PAGE and haem staining (data not shown) and by measurements of whole-cell TMPD oxidation (Table 3). While DP301 and DP308 oxidized TMPD at rates comparable to Pd1222, mutants DP302-DP307 and DP309 did not oxidize TMPD, reflecting the complete absence of $c$-type cytochromes in these mutants; both a functional cytochrome oxidase and $c$-type cytochrome(s) are required for TMPD oxidation (Keilin, 1966). The presence of $c$-type cytochromes in DP301 indicates that the ORF117 gene product is not required for $c$-type cytochrome biosynthesis and suggests that DP302 is deficient in $c$-type cytochrome assembly because the $\Omega$ interposon blocks expression of one or more $\mathrm{ccm}$ genes. Disruption of hisH (in DP308) had no effect on c-type cytochrome biogenesis.

\section{Cytochrome $\mathrm{aa}_{3}$ biogenesis in the interposon mutants}

The ccmG:: $\Omega$ mutant DP307 lacks spectroscopically detectable cytochrome $a a_{3}$, and cytoplasmic membranes prepared from aerobically grown DP307 oxidize reduced horse heart cytochrome $c$ at a much reduced rate compared to membranes from Pd1222 (Page \& Ferguson, 1997). This was also observed for DP309 $(\Delta c c m C D G:: \Omega)$. In contrast, cytoplasmic membranes from DP301-DP305 and DP308 contained wild-type levels of cytochrome $a a_{3}$ as judged by spectroscopy of solubilized membrane fractions (Fig. 3a), and oxidized cytochrome $c$ at rates similar to membranes from Pd1222 (Table 3), indicating that $\Omega$ insertions in $c \mathrm{~cm} A, c \mathrm{cmB}$ or $\mathrm{ccm} C$ have little or no effect on biosynthesis of the $a a_{3}$ type cytochrome oxidase. Membranes from DP306 $(c \mathrm{cmD}:: \Omega)$ contained an intermediate level of spectroscopically detectable cytochrome $a a_{3}$ compared to membranes from Pd1222, and oxidized cytochrome $c$ at an intermediate rate, suggesting either that $c \mathrm{cmD}$ contributes to biosynthesis of the $a a_{3}$-type cytochrome oxidase or that $\Omega$ integration in the central region of $\mathrm{ccmD}$ may reduce but not eliminate expression of $\mathrm{ccm} G$. 

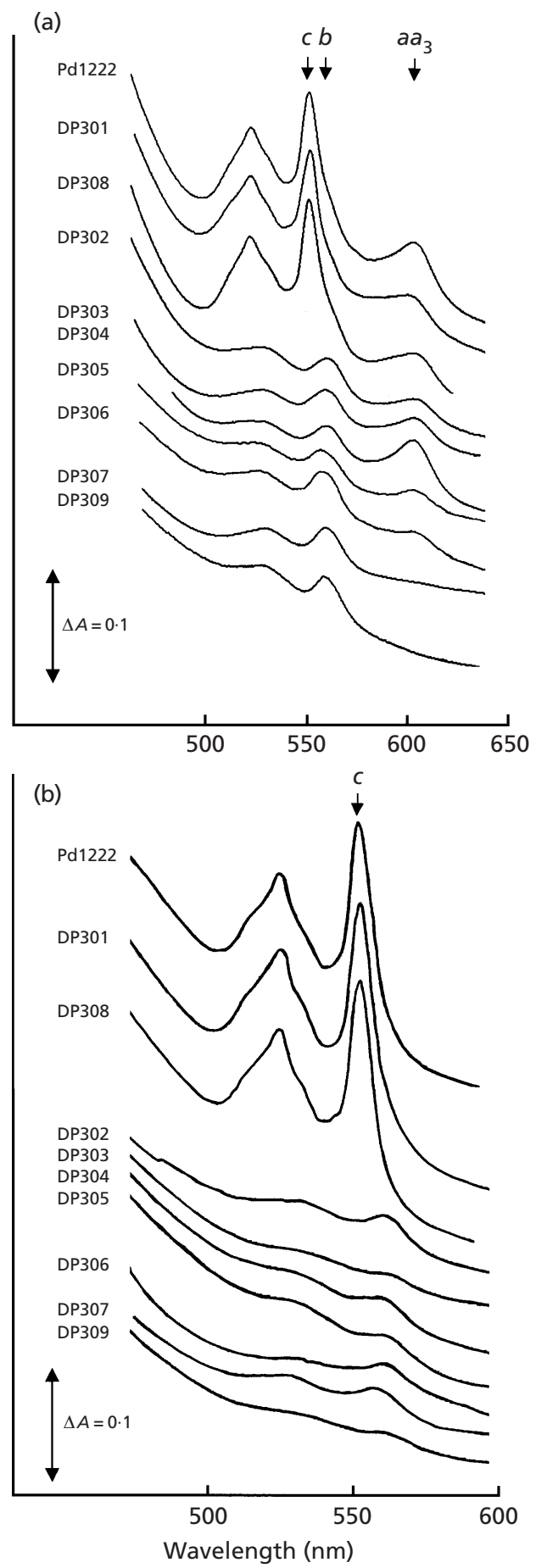

Fig. 3. Visible absorption spectra of (a) Nonidet-P-40-solubilized membranes and (b) total soluble extracts from Pd1222 and the mutant strains DP301-DP309. The alpha absorption bands for cytochromes $a a_{3}, b$ and $c$ are indicated. Strains were grown with choline to maximize aerobic c-type cytochrome production. Samples were adjusted to a protein concentration of $10 \mathrm{mg} \mathrm{ml}^{-1}$ (solubilized membranes) or $15 \mathrm{mg} \mathrm{ml}^{-1}$ (soluble extract), reduced by addition of sodium dithionite and spectra measured against a buffer reference.

The observation that DP306 grown in the presence of 1 or $2 \mathrm{mM}$ DTT synthesized cytochrome $a a_{3}$ at near wildtype levels (data not shown) supports the latter in- terpretation; we have shown previously that growth in the presence of DTT restores synthesis of cytochrome $a a_{3}$ in DP307 (Page \& Ferguson, 1997).

\section{Growth of the interposon mutants on rich media}

We have previously reported that DP307 (ccmG:: $\Omega$ ) is incapable of growth on rich media (Page \& Ferguson, 1997). This phenotype is not a consequence of $c$-type cytochrome deficiency; several other mutants of $P$. denitrificans that are also pleiotropically deficient in $c$ type cytochromes grow as well on rich media as the wild-type Pd1222 (Page \& Ferguson, 1995; Pearce et al., 1998 ). When the $\Omega$ mutants were tested for their ability to adapt to growth on LB, it was observed that they fell into three groups (Fig. 4). DP301 and DP308 grew as fast, and to a similar final $\mathrm{OD}_{650}$, as Pd1222. DP302, DP303, DP304 and DP306 also grew on LB, but with slightly reduced growth rates compared to Pd1222; DP306 also exhibited an extended lag phase.

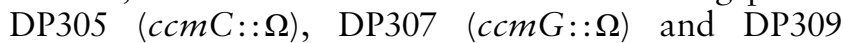
$(\triangle c c m C D G:: \Omega)$ failed to grow on LB. In the light of the cytochrome $a a_{3}$ biogenesis results (see above), it appears likely that the extended lag phase exhibited by DP306 (ccmD:: $\Omega$ ) when inoculated into LB was due to attenuated expression of $c \mathrm{~cm} G$. Similarly, the slightly reduced growth rates of DP302, DP303 and DP304 could be explained by a weak polarity of $\Omega$ insertions in $c \mathrm{~cm} A$, $c c m B$ or the $c c m A B$ promoter region on expression of $c \mathrm{~cm} C$. What is clear from the cytochrome $a a_{3}$ biogenesis data, however, is that the failure of DP305 to grow in LB does not result from polarity of the $\Omega$ cassette in $\mathrm{ccm} C$ on either $\mathrm{ccmD}$ or $\mathrm{ccm}$. Whilst some growth of DP307 on LB was observed after extended incubation (24-48 h), no growth of DP305 or of DP309 was observed even after incubations of $72 \mathrm{~h}$. This suggests that the richmedia-intolerant phenotype conferred by $c c m C$ disruption is more severe than that conferred by disruption of $\mathrm{cm}$ G. We have reported previously that DP307 will grow on nutrient agar supplemented with 1-2 mM DTT (Page \& Ferguson, 1997); in contrast, neither DP305 nor DP309 formed colonies on nutrient agar supplemented with DTT at various concentrations between $0.05 \mathrm{mM}$ and $5 \mathrm{mM}$.

\section{Sensitivity of the interposon mutants to growth inhibition by 2-hydroxyethyldisulphide (HEDS)}

Following from the observation that DP305 $(\mathrm{ccm} C:: \Omega)$ and DP309 $(\Delta c \mathrm{~cm} C D G:: \Omega)$ are, like DP307 (ccmG:: $\Omega$ ), defective for growth in rich media, we analysed the effect of the oxidized thiol compound HEDS (the oxidized form of $\beta$-mercaptoethanol) on the growth of the other $\Omega$ mutants. We have reported previously that disruption of $\mathrm{ccmG}$ confers increased sensitivity to oxidized thiol compounds on $P$. denitrificans and that this may account for the failure of DP307 to grow in rich media (Page \& Ferguson, 1997). DP305 and DP309 were highly sensitive to growth inhibition by HEDS (Fig. 5), consistent with the results of the LB growth experiment. In contrast, DP301 and DP308 were no more sensitive to HEDS than was Pd1222. DP302, DP303 and DP304 were 
Table 3. Selected phenotypic data for Pd1222 and the various $\Omega$ interposon mutants in the ORF117-ccmABCDG-hisH gene region

\begin{tabular}{|c|c|c|c|c|c|c|}
\hline \multirow[t]{2}{*}{ Strain and mutation } & \multirow{2}{*}{$\begin{array}{l}c \text {-type } \\
\text { cytochrome } \\
\text { content* }\end{array}$} & \multicolumn{2}{|c|}{$\begin{array}{c}\text { Specific activity } \\
{\left[\text { nmol } \min ^{-1}(\text { mg protein })^{-1}\right]}\end{array}$} & \multirow[t]{2}{*}{$\begin{array}{l}\text { Growth on } \\
\text { LB agar }\end{array}$} & \multirow{2}{*}{$\begin{array}{l}\text { Growth on LB } \\
\text { agar containing } \\
1 \mathrm{mM} \mathrm{DTT}\end{array}$} & \multirow{2}{*}{$\begin{array}{l}\text { Diameter of cleared } \\
\text { zone formed on CAS } \\
\text { plates }(\mathrm{mm}) \mathbb{S}\end{array}$} \\
\hline & & $\begin{array}{c}\text { cytochrome-c } \\
\text { oxidase } \dagger\end{array}$ & $\begin{array}{c}\text { TMPD } \\
\text { oxidase } \neq\end{array}$ & & & \\
\hline PD1222 (wild -type) & +++ & $1408 \pm 146$ & $259 \pm 22$ & + & + & $13 \cdot 6 \pm 0 \cdot 5$ \\
\hline DP301 (ORF117 XhoI:: $\Omega$ ) & +++ & $1148 \pm 130$ & $283 \pm 26$ & + & + & $14 \cdot 2 \pm 2 \cdot 3$ \\
\hline DP302 (ORF117 EcoRV:: $\Omega)$ & - & $1204 \pm 117$ & - & + & + & $13 \cdot 9 \pm 2 \cdot 0$ \\
\hline DP303 (ccmA:: $\Omega)$ & - & $1424 \pm 148$ & - & + & + & $12 \cdot 5 \pm 0 \cdot 7$ \\
\hline DP304 (ccmB:: $\Omega)$ & - & $1436 \pm 126$ & - & + & + & $13 \cdot 0 \pm 1 \cdot 0$ \\
\hline DP305 (ccmC:: $\Omega)$ & - & $840 \pm 90$ & - & - & - & $7 \cdot 3 \pm 1 \cdot 0$ \\
\hline DP306 (ccmD:: $\Omega)$ & - & $204 \pm 56$ & - & + & + & $9 \cdot 3 \pm 1 \cdot 7$ \\
\hline DP307 (ccmG:: $\Omega)$ & - & $44 \pm 19$ & - & - & + & $7 \cdot 5 \pm 0 \cdot 5$ \\
\hline DP308 (bis $H:: \Omega$ ) & +++ & $1168 \pm 103$ & $232 \pm 25$ & + & + & $14 \cdot 1 \pm 1 \cdot 9$ \\
\hline DP309 ( $\triangle c c m C D G:: \Omega)$ & - & $56 \pm 18$ & - & - & - & $7 \cdot 1 \pm 0 \cdot 8$ \\
\hline
\end{tabular}

*As judged by spectroscopy and haem staining: +++ , similar to Pd1222; - , undetectable within limits of assay.

† Oxidation of reduced horse heart cytochrome $c$; values are means of two determinations on each of two separate cultures.

$\ddagger \mathrm{O}_{2}$ consumption; values are means of two determinations on each of two separate cultures.

$\$$ Mean of six determinations.

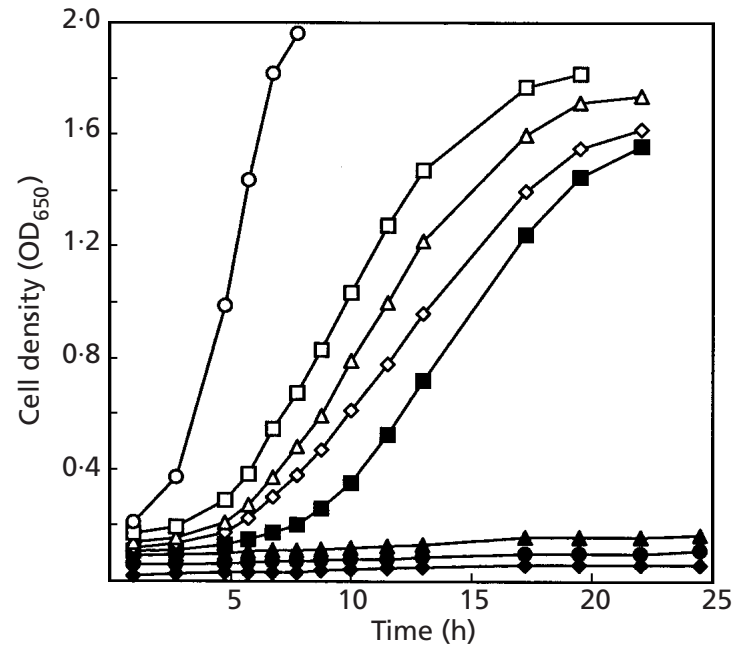

Fig. 4. Capacity of the mutant strains for growth in a rich medium. Cells pregrown in succinate minimal medium were inoculated into $L$ broth and cell density $\left(\mathrm{as}_{\mathrm{OD}}{ }_{650}\right)$ monitored. O, Pd1222; $\square$, DP302; $\triangle$, DP303; $\diamond$, DP304; 0, DP305; DP306; $\Delta$, DP307; $\diamond$, DP309. The growth curves exhibited by DP301 and DP308 were identical to that exhibited by Pd1222 and have been omitted for the sake of clarity.

slightly more sensitive to HEDS than Pd1222, whilst DP306 was more sensitive to HEDS than DP302, DP303 and DP304 but less sensitive than DP307. DP305 and DP309 were significantly more sensitive to HEDS than DP307. These findings reflect and confirm those obtained for growth of the strains on LB.

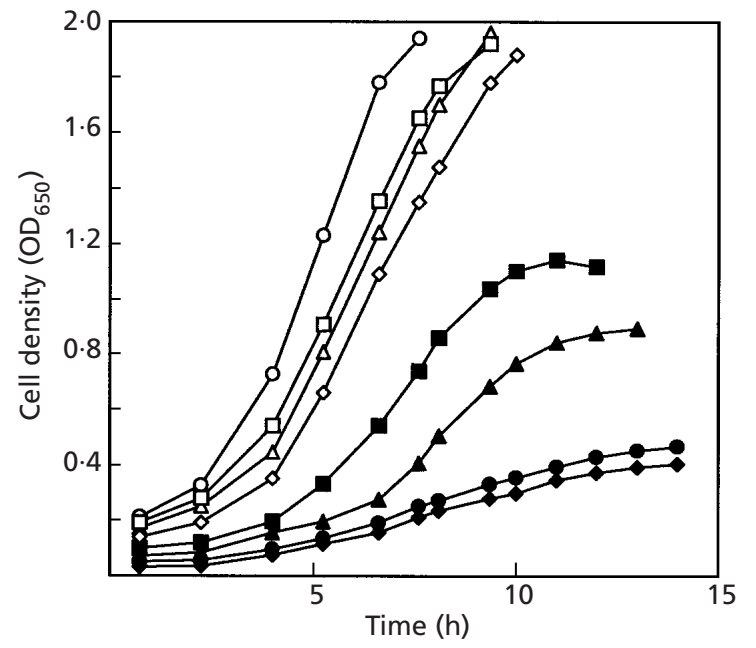

Fig. 5. Sensitivity of the mutant strains to growth inhibition by an oxidized thiol compound. Cells pregrown in succinate minimal medium were inoculated into succinate minimal medium containing $3 \mathrm{mM}$ HEDS and cell density (as $\mathrm{OD}_{650}$ ) monitored. $\bigcirc$, Pd1222; $\square$, DP302; $\triangle$, DP303; $\diamond, D P 304 ; 0$, DP305; DP306; $A$, DP307; $\bullet$ DP309. The growth curves exhibited by DP301 and DP308 were identical to that exhibited by $\mathrm{Pd} 1222$ and have been omitted for the sake of clarity.

\section{Siderophore biosynthesis and secretion in the interposon mutants}

A mutation producing a defect in siderophore biosynthesis and/or secretion in Pseudomonas fluorescens has recently been mapped to a gene, cytA, that is homologous to $c \mathrm{cmC}$; it was found that disruption of 
the adjacent $c c m D$-homologous gene, $c y t B$, did not affect this process, although both $c y t A$ and $c y t B$ mutants were pleiotropically deficient in $c$-type cytochromes (Gaballa et al., 1996). However, the possible involvement of homologues of $\mathrm{CcmA}, \mathrm{CcmB}$ or $\mathrm{CcmG}$ in siderophore biosynthesis and/or secretion has not previously been investigated. P. denitrificans is known to synthesize several catecholate siderophores (Tait, 1975), and it produced a cleared zone in the CAS plate assay. Siderophore biosynthesis and/or secretion were apparently unaffected by the mutations in DP301-304 and DP308. Mutants DP305 (ccmC:: $\Omega$ ), DP307 ( $\mathrm{cm} G:: \Omega)$ and DP309 $(\Delta c \mathrm{~cm} C D G:: \Omega)$ produced cleared zones of reduced diameter (about twofold), compared to those produced by Pd1222, indicative of reduced biosynthesis and/or secretion of one or more siderophores in these strains. DP306 (ccmD:: $\Omega$ ) produced a cleared zone of intermediate size (Table 3). The results obtained for cytochrome $a a_{3}$ biogenesis (see above) suggest that this effect can be attributed to polarity of the $\Omega$ interposon in $c c m D$ on the expression of $c c m G$. Thus, these results implicate $\mathrm{CcmC}$ and $\mathrm{CcmG}$, but not $\mathrm{CcmA}, \mathrm{CcmB}$ or $\mathrm{CcmD}$, in the biosynthesis and/or secretion of one or more siderophores, or the regulation of these processes, in $P$. denitrificans.

\section{DISCUSSION}

The present work extends our analysis of $c$-type cytochrome biogenesis in $P$. denitrificans, an organism whose exceptional nutritional versatility is closely linked to its ability to synthesize a considerable array of these electron transport proteins (Baker et al., 1998) The mutational analyses reported here indicate that $c c m A$, $c \mathrm{cmB}, \mathrm{ccm} C, \mathrm{ccmD}$ and $\mathrm{ccm} G$ are all required for $c$-type cytochrome biosynthesis in $P$. denitrificans, but it appears likely that only $c \mathrm{cmG}$ is required for $a a_{3}$-type cytochrome oxidase biogenesis. Our results also indicate that $\mathrm{CcmC}$ and $\mathrm{CcmG}$ remain functional in the absence of $\mathrm{CcmA}, \mathrm{CcmB}$ or $\mathrm{CcmD}$, or each other; if this was not the case, all mutations in the $c c m A B C D G$ operon would yield the same phenotype. Phenotypic analysis of the $\Omega$ mutants, together with complementation studies, suggests that there may be three promoters in the $c c m A B C D G$ gene region, one upstream of $c c m A$, a second upstream of $\mathrm{ccmC}$ and a third upstream of $\mathrm{ccm} G$. However, further work will be required to define the transcriptional organization of these genes.

We have not previously reported the effects of $c \mathrm{cmC}$ or $c c m D$ disruption in $P$. denitrificans. This series of analyses has shed little light on the role of $\mathrm{CcmD}$. Although $\Omega$ insertion in $c c m D$ has some effect on cytochrome $a a_{3}$ biogenesis, tolerance of oxidized thiol compounds and siderophore biosynthesis/secretion, it appears likely that this is due to a reduction in $\mathrm{cmG}$ expression; in Pseudomonas fluorescens, disruption of the $c c m D$-homologous gene $c y t B$ has no effect on siderophore biosynthesis/secretion (Gaballa et al., 1996). Previous discussions of the function of CcmC have always focused on its assumed role as a component of the proposed $\mathrm{HelA}_{2} \mathrm{BC} / \mathrm{HelA}_{2} \mathrm{BCD} \mathrm{ABC}$-transporter
(Thöny-Meyer, 1997; Kranz et al., 1998). The finding that $c \mathrm{cmC}$ disruption leads to a rich media growth defect, HEDS sensitivity and a defect in siderophore synthesis and/or secretion, whereas disruption of $c \mathrm{cmA}$ or $c \mathrm{cmB}$ does not, was therefore completely unexpected, indicating that $\mathrm{CcmC}$ can carry out at least one of its cellular functions in the absence of $\mathrm{CcmA}$ or $\mathrm{CcmB}$. The possibility of a unique role for $\mathrm{CcmC}$ was suggested by the finding that the $c c m C$-homologous gene, $c y t A$, of Pseudomonas fluorescens is required for both siderophore biosynthesis and/or secretion and for $c$ type cytochrome biogenesis, but the $c \mathrm{cmD}$-homologous gene $c y t B$ is required only for the latter function (Gaballa et al., 1996); however these authors were unable to investigate the effects of the disruption of $c \mathrm{cmA}$ - or ccmB-homologous genes in Pseudomonas fluorescens because these were not found upstream of $c y t A$. One possible interpretation of our results is that $\mathrm{CcmC} \mathrm{might}$ not after all be a component of the putative ABCtransporter, which might instead have the subunit structure $\mathrm{CcmA}_{2} \mathrm{~B}_{2}$ (like KpsM $\mathrm{T}_{2}$ of E. coli; Higgins, 1992) or $\mathrm{CcmA}_{2} \mathrm{~B}_{2} \mathrm{D}$, whilst $\mathrm{CcmC}$ functions either independently or as a component of another complex. Indeed, while this manuscript was being revised a paper reporting closely related work (Schulz et al. 1999) was published. These authors report that haem transfer to the E. coli haem chaperone CcmE, a step required for cytochrome $c$ maturation (Schulz et al. 1998), was blocked by disruption of $\mathrm{ccm} C$ but not by disruption of $c c m A$ or $c c m B$, and conclude that the putative ABCtransporter comprises only $\mathrm{CcmAB}$. However, the evidence that in R. capsulatus HelA can be co-immunoprecipitated with $\mathrm{HelC}$ and that $\mathrm{HelC}$ is required for stability of HelA (Goldman et al., 1997) clearly indicates that that these proteins interact in vivo. Furthermore, this is consistent with a theoretical study showing that both $\mathrm{CcmB} / \mathrm{HelB}$ and $\mathrm{CcmC} / \mathrm{HelC}$ contain a conserved sequence motif characteristic of the membrane-integral components of bacterial ABC-transporters and proposed to mediate their interaction with the more hydrophilic ATPase component, in this case CcmA/ HelA (Page et al., 1997). These results suggest that $\mathrm{CcmC}$ is perhaps more likely to be bifunctional, acting both as a component of the postulated $\mathrm{CcmA} \mathrm{A}_{2} \mathrm{BC} / \mathrm{CcmA}_{2} \mathrm{BCD}$-transporter and in another role, either while remaining associated with $\mathrm{CcmA}$ and $\mathrm{CcmB}$ $( \pm \mathrm{CcmD})$, or independently, or as a component of another complex.

This uncertainty is reflected in the physical organization of the $P$. denitrificans $c c m A B C D G$ gene region. While $c \mathrm{~cm} A$ and $c \mathrm{cmB}$ appear to be translationally coupled via a small open reading frame, ORF5, $c \mathrm{~cm} C$ is separated from $c \mathrm{cmB}$ by a $60 \mathrm{bp}$ untranslated region and appears instead to be translationally coupled to $\mathrm{ccmD}$ and $\mathrm{ccm} G$ (Page et al., 1997). A similar organization of ccmA-, $\mathrm{ccmB}$ - and $\mathrm{ccm} C$-homologous genes is found in other organisms, for example R. capsulatus, Bradyrhizobium japonicum and other $\alpha$-proteobacteria (Thöny-Meyer, 1997), whilst in at least one $\gamma$-proteobacterium, Pseudomonas fluorescens ATCC17400 (Gaballa et al., 
1996), a number of bacteria from other divisions, and mitochondrial and chloroplast genomes (Kranz et al., 1998), genes homologous to $c c m C$ are found without adjacent $c c m A$ - or $c c m B$-homologous genes.

The putative $\mathrm{CcmA}_{2} \mathrm{BC} / \mathrm{CcmA}_{2} \mathrm{BCD}$-transporter has been postulated to translocate haem (Thöny-Meyer, 1997; Kranz et al., 1998). We have argued on the basis of sequence analysis that this is unlikely to be the case (Page et al., 1997), and the observation that mutants of E. coli carrying in-frame deletions in $\mathrm{ccm} A$ and $\mathrm{ccmB}$ can assemble the periplasmic $b$-type cytochrome $b_{562}$ (Throne-Holst et al., 1997) would appear to support this argument. However, the results of Schulz et al. (1999) suggest that the $\mathrm{CcmC}$ proteins (and the related proteins CcmF and CcsA; Xie \& Merchant, 1998) may indeed bind haem. In the light of these new data, the involvement of $P$. denitrificans $\mathrm{CcmC}$ and the CcmChomologous CytA of Psendomonas fluorescens ATCC 17400 (Gaballa et al., 1996) in both cytochrome $c$ assembly and the biosynthesis and/or secretion of siderophores suggests that the $\mathrm{CcmC}$ homologues, at least, may have a general affinity for iron chelates. In the case of the Pseudomonas fluorescens CytA, these two activities have been resolved; some site-directed mutants of CytA function in $c$-type cytochrome assembly but cannot promote the biosynthesis and/or secretion of siderophores, whilst others promote the biosynthesis/ secretion of siderophores but cannot function in $c$-type cytochrome biosynthesis (Gaballa et al., 1998). The challenge now is to integrate these various observations into a scheme for $\mathrm{CcmC}$ function.

Intriguingly, the phenotypes resulting from disruption of $c \mathrm{cmC}$ (DP305) and $\mathrm{ccmG}$ (DP307) are rather similar. We have previously suggested, based partly on the sensitivity of DP307 to oxidized thiol compounds (HEDS, oxidized DTT and one or more components of rich media), that $\mathrm{CcmG}$ is a protein-disulphide reductase interacting with a range of periplasmic proteins in vivo (Page \& Ferguson, 1997). It is presumed that exposure to oxidized thiol compounds causes the formation of aberrant protein disulphide bonds within or between proteins and that when CcmG is present it confers a degree of protection by reducing these bonds when they occur in or between periplasmic proteins; DTT can substitute for CcmG. Our observation that disruption of $\mathrm{ccmC}$ also results in sensitivity to growth inhibition by HEDS and failure to grow on rich media suggests that $\mathrm{CcmC}$ may contribute in some way to disulphide bond reduction by CcmG, but how is not obvious. CcmC cannot simply be acting to stabilize CcmG, because $\mathrm{ccm} C$ disruption does not lead to the loss of cytochrome $a a_{3}$ as is observed on disruption of $c c m G$, and because the rich media growth defect of DP305 ( $\mathrm{cm} C:: \Omega)$ cannot be overcome by supplementation with DTT. A role for $\mathrm{CcmC}$ in the provision of reducing power to $\mathrm{CcmG}$ can be ruled out for the same reasons. One hypothesis we are currently considering is that $\mathrm{CcmC}$ may bind and (perhaps partially or locally) unfold certain target proteins such that buried disulphide bonds are made accessible for reduction by CcmG or by added
DTT; in the absence of $\mathrm{CcmC}$ these bonds would remain buried and thus inaccessible to reduction by either CcmG or DTT. Whether this is the case, and if so whether this group of target proteins includes the apocytochromes $c$, remains to be determined.

\section{ACKNOWLEDGEMENTS}

We gratefully thank D. Kelly for pARO181, pHP45 $\Omega$ and pUX $\Omega ; K$. Yeoman for advice on analysis of siderophore synthesis/secretion; and Pierre Cornelis, Christine Baysse, Esther Tomlinson and Simon Baker for useful discussions. This work was supported by BBSRC grant C08007 to S. J.F. This is a contribution from the Oxford Centre for Molecular Sciences, which is supported by the BBSRC, EPSRC and MRC.

\section{REFERENCES}

Alefounder, P. R. \& Ferguson, S. J. (1981). A periplasmic location for methanol dehydrogenase from Paracoccus denitrificans: implications for proton pumping by cytochrome $a a_{3}$. Biochem Biophys Res Commun 98, 778-784.

Bagdasarian, M., Lürz, R., Rückert, B., Franklin, F. C. H., Bagdasarian, M. M., Frey, J. \& Timmis, K. N. (1981). Specificpurpose plasmid cloning vectors. II. Broad host range, high copy number RSF1010-derived vectors, and a host-vector system for gene cloning in Pseudomonas. Gene 16, 237-247.

Baker, S. C., Ferguson, S. J., Ludwig, B., Page, M. D., Richter, O. M. \& van Spanning, R. J. M. (1998). Molecular genetics of the genus Paracoccus: metabolically versatile bacteria with bioenergetic flexibility. Microbiol Mol Biol Rev 62, 1046-1078.

Beckman, D. L. \& Kranz, R. G. (1993). Cytochromes $c$ biogenesis in a photosynthetic bacterium requires a periplasmic thioredoxinlike protein. Proc Natl Acad Sci USA 90, 2179-2183.

Beckman, D. L., Trawick, D. R. \& Kranz, R. G. (1992). Bacterial cytochrome $c$ biogenesis. Genes Dev 6, 268-283.

Burnell, J. N., John, P. \& Whatley, F. R. (1975). The reversibility of active sulphate transport in membrane vesicles of Paracoccus denitrificans. Biochem J 150, 527-536.

Ditta, G., Stanfield, S., Corbin, D. \& Helinski, D. R. (1980). Broad host range DNA cloning systems for Gram-negative bacteria: construction of a gene bank of Rhizobium meliloti. Proc Natl Acad Sci USA 77, 7347-7351.

Gaballa, A., Koedam, N. \& Cornelis, P. (1996). A cytochrome $c$ biogenesis gene involved in pyoverdine production in Pseudomonas fluorescens ATCC 17400. Mol Microbiol 21, 777-785.

Gaballa, A., Baysse, C., Koedam, N., Muyldermans, S. \& Cornelis, P. (1998). Different residues in periplasmic domains of the CcmC inner membrane protein of Pseudomonas fluorescens ATCC 17400 are critical for cytochrome $c$ biogenesis and pyoverdinemediated iron uptake. Mol Microbiol 30, 547-555.

Goldman, B. S., Beckman, D. L., Bali, A., Monika, E. M., Gabbert, K. K. \& Kranz, R. G. (1997). Molecular and immunological analysis of an $\mathrm{ABC}$ transporter complex required for cytochrome $c$ biogenesis. J Mol Biol 268, 724-738.

Harms, N. \& van Spanning, R. (1991). C 1 metabolism in Paracoccus denitrificans. J Bioenerg Biomembr 23, 187-210.

Higgins, C. F. (1992). ABC transporters: from microorganisms to man. Annu Rev Cell Biol 8, 67-113.

Keen, N. T., Tamaki, S., Kobayashi, D. \& Trollinger, D. (1988). Improved broad-host-range vectors for DNA cloning in Gramnegative bacteria. Gene 70, 191-197. 
Keilin, D. (1966). The History of Cell Respiration and Cytochrome. Edited by J. Keilin. Cambridge: Cambridge University Press.

Kranz, R. G. \& Beckman, D. L. (1995). Cytochrome biogenesis. In Anoxygenic photosynthetic bacteria, pp. 709-723. Edited by R. E. Blankenship, M. T. Madigan \& C. E. Bauer. Amsterdam: Kluwer.

Kranz, R., Lill, R., Goldman, B., Bonnard, G. \& Merchant, S. (1998). Molecular mechanisms of cytochrome $c$ biogenesis: three distinct systems. Mol Microbiol 29, 383-396.

Marrs, B. \& Gest, H. (1973). Genetic mutations affecting the respiratory electron-transport system of the photosynthetic bacterium Rhodopseudomonas capsulata. J Bacteriol 114, 1045-1051.

Oozeer, F., Page, M. D., Ferguson, S. J. \& Goodwin, P. M. (1993). Phenotypic characterization of $c$-type-cytochrome-deficient mutants of Methylobacterium extorquens AM1 and identification of two chromosomal regions essential for the production of $c$ type cytochromes. J Gen Microbiol 139, 11-19.

Page, M. D. \& Ferguson, S. J. (1995). Cloning and sequence analysis of $c y c H$ gene from Paracoccus denitrificans: the $c y c H$ gene product is required for assembly of all $c$-type cytochromes, including cytochrome $c_{1}$. Mol Microbiol 15, 307-318.

Page, M. D. \& Ferguson, S. J. (1997). Paracoccus denitrificans $\mathrm{CcmG}$ is a periplasmic protein-disulphide oxidoreductase required for $c$ - and $a a_{3}$-type cytochrome biogenesis; evidence for a reductase role in vivo. Mol Microbiol 24, 977-990.

Page, M. D., Pearce, D. A., Norris, H. A. C. \& Ferguson, S. J. (1997). The Paracoccus denitrificans ccm $A, B$ and $C$ genes: cloning and sequencing, and analysis of the potential of their products to form a haem or apo- $c$-type cytochrome transporter. Microbiology 143 , 563-576.

Page, M. D., Sambongi, Y. \& Ferguson, S. J. (1998). Contrasting routes of $c$-type cytochrome assembly in mitochondria, chloroplasts and bacteria. Trends Biochem Sci 267, 103-108.

Parke, D. (1990). Construction of mobilizable vectors derived from plasmids RP4, pUC18 and pUC19. Gene 93, 135-137.

Pearce, D. A., Page, M. D., Norris, H. A. C., Tomlinson, E. J. \& Ferguson, S. J. (1998). Identification of the contiguous Paracoccus denitrificans $c \mathrm{cmF}$ and $\mathrm{ccmH}$ genes : disruption of $c \mathrm{cmF}$, encoding a putative transporter, results in formation of an unstable apocytochrome $c$ and deficiency in siderophore production. Microbiology 144, 467-477.

Prentki, K. \& Krisch, H. M. (1984). In vitro insertional mutagenesis with a selectable DNA fragment. Gene 29, 303-313.
Sambrook, J., Fritsch, E. F. \& Maniatis, T. (1989). Molecular Cloning: a Laboratory Manual, 2nd edn. Cold Spring Harbor, NY : Cold Spring Harbor Laboratory.

Schulz, H., Hennecke, H. \& Thöny-Meyer, L. (1998). Prototype of a heme chaperone essential for cytochrome $c$ maturation. Science 281, 1197-1200.

Schulz, H., Fabianek, R. A., Pellicoli, E. C., Hennecke, H. \& ThönyMeyer, L. (1999). Haem transfer to the haem chaperone CcmE during cytochrome $c$ maturation requires the $\mathrm{CcmC}$ protein, which may function independently of the ABC-transporter CcmAB. Proc Natl Acad Sci USA 96, 6462-6467.

Schwyn, B. \& Neilands, J. B. (1987). Universal chemical assay for the detection and determination of siderophores. Anal Biochem 160, 47-56.

Simon, R., Priefer, U. \& Pühler, A. (1983). A broad host range mobilization system for in vivo genetic engineering: transposon mutagenesis in Gram-negative bacteria. Bio/Technology 1, $37-45$.

Tait, G. H. (1975). The identification and biosynthesis of siderophores formed by Micrococcus denitrificans. Biochem J 146, 191-204.

Thöny-Meyer, L. (1997). Biogenesis of respiratory cytochromes in bacteria. Microbiol Mol Biol Rev 61, 337-376.

Throne-Holst, M., Thöny-Meyer, L. \& Hederstedt, L. (1997). Escherichia coli $\mathrm{ccm}$ in-frame deletion mutants can produce periplasmic cytochrome $b$ but not cytochrome $c$. FEBS Lett $\mathbf{4 1 0}$, 351-355.

de Vries, G. E., Harms, N., Hoogedijk, J. J. \& Stouthamer, A. H. (1989). Isolation and characterisation of Paracoccus denitrificans mutants with increased conjugation frequencies and pleiotropic loss of a (nGATCn) DNA-modifying property. Arch Microbiol $152,52-57$.

Willison, J. C. \& John, P. (1979). Mutants of Paracoccus denitrificans deficient in $c$-type cytochromes. J Gen Microbiol 115, 443-450.

Xie, Z. \& Merchant, S. (1998). A novel pathway for cytochromes $c$ biogenesis in chloroplasts. Biochim Biophys Acta 1365, 309-318.

Yanisch-Perron, C., Vieira, J. \& Messing, J. (1985). Improved M13 phage cloning vectors and host strains: nucleotide sequences of the M13mp18 and pUC19 vectors. Gene 33, 103-119.

Received 1 April, 1999; revised 6 July, 1999; accepted 22 July 1999. 